\title{
Cardiac Differentiated Adult Human Bone Marrow Stem Cells Express Sarcomeric and Structural Proteins of Cardiomyocytes
}

\author{
W.S.N.Shim, ${ }^{*}$ G.M.Y.Tan, ${ }^{*}$ and P.Wong* \\ * Research \& Development Unit, National Heart Centre, 17 Third Hospital Ave, Singapore 168752
}

Mammalian heart has previously been considered a terminally differentiated organ that is incapable of self-renewal. Recent evidence suggests that myocardium may have some capacity to undergo limited self-repair following acute injury.

Bone marrow mesenchymal stem cells have the ability to differentiate into cardiomyocytes following genomic demethylation using 5-azacytidine [1] or co-culturing with rodent cardiomyocytes [2]. Transplanting exogenous cells that are structurally and functionally congruent with the myocardium to augment the self-repair process is hence logical. However, co-culturing technique and 5-aza treatment are unlikely to be clinically applicable due to their low efficacy and potentially harmful side effects. We investigate if adult human mesenchymal stem cells can be differentiated ex vivo into cardiomyocyte-like cells (CLCs), independent of cytotoxic agents or coculturing technique.

Sternum bone marrow stem cells were isolated from 25 patients undergoing coronary artery bypass surgery. These stem cells were differentiated in cardiomyogenic medium containing insulin, dexamethasone and ascorbic acid. Differentiation towards CLCs was determined by expression of cardiomyocyte-specific proteins 2 weeks after induction.

Differentiated cells expressed cardiac-specific transcription factors and multiple contractile proteins that are associated with cardiomyocytes. Thin myofibrils associated sarcomeric proteins were detected early in the cells, with cardiac troponin I, sarcomeric $\alpha$-actinin, sarcomeric tropomyosin and cardiac titin among the first expressed. Some CLCs developed a nascent cardiomyocyte phenotype with laterally aligned Z-bodies forming nascent cross-striated Z bands and sarcomeres with regular periodicities after successive passage in differentiated cultures.

Cells with cardiomyocyte characteristics can be derived from adult human bone marrow using a non-toxic culture medium. These lineage-defined cardiomyocyte-like cells may be potentially very useful for repairing damaged myocardium.

\section{References}

[1] S. Makino et al., J Clin Invest. 103 (1999) 697.

[2] S. Fukuhara et al., J Thorac Cardiovasc Surg. 125 (2003) 1470.

[3] This work was supported by SingHealth Cluster Research Fund (SU034/02 \& EX069/04), Singapore Medical Research Council (NMRC0729/2003), Singapore Biomedical Research Council (BMRC04/1/32/19/355) and Singapore Heart Foundation. 
TABLE 1. Expression of sarcomeric proteins in cardiomyocyte-like cells

Antibody Cardiomyocyte-like Cells

Cardiac titin, clone T11

Cardiac troponin I, clone $2 Q 1100$

Sarcomeric $\alpha$-actin, clone ZMSA5

Sarcomeric $\alpha$-actinin, clone EA-35

Sarcomeric $\alpha$-tropomyosin, clone $\mathrm{CH} 1$

Sarcomeric MHC, clone MF20

SERCA2 ATPase, clone IID8

L-type $\alpha 1 \mathrm{c} \mathrm{Ca} 2+$ channel, polyclonal

Connexin-43, polyclonal

Desmin, clone DE-U-10

Myosin light chain-1, polyclonal

Phospholamban, clone 2D12

GATA-4, polyclonal

Cardiac $\alpha / \beta$ MHC, clone F26.2D11

Cardiac troponin C, clone F8.287

Cardiotin, clone $S R-2$

Cardiac troponin T, clone 13-11

Atrial natriuretic peptide, clone 23/1

Myosin light chain-2, clone F109.3E1

MyoD, clone $5.8 \mathrm{~A}$

Skeletal muscle MHC, clone MY-32

Slow muscle MHC, clone NOQ7.5.4D

+++
+++
+++
+++
+++
+++
+++
+++
++
++
++
++
++
+
+
+
+-
$+/$
-
-
-
-

Expression Levels: “+/_": weakly positive, “+”: positive, “++": moderately positive, “+++": strongly positive, “-": negative.
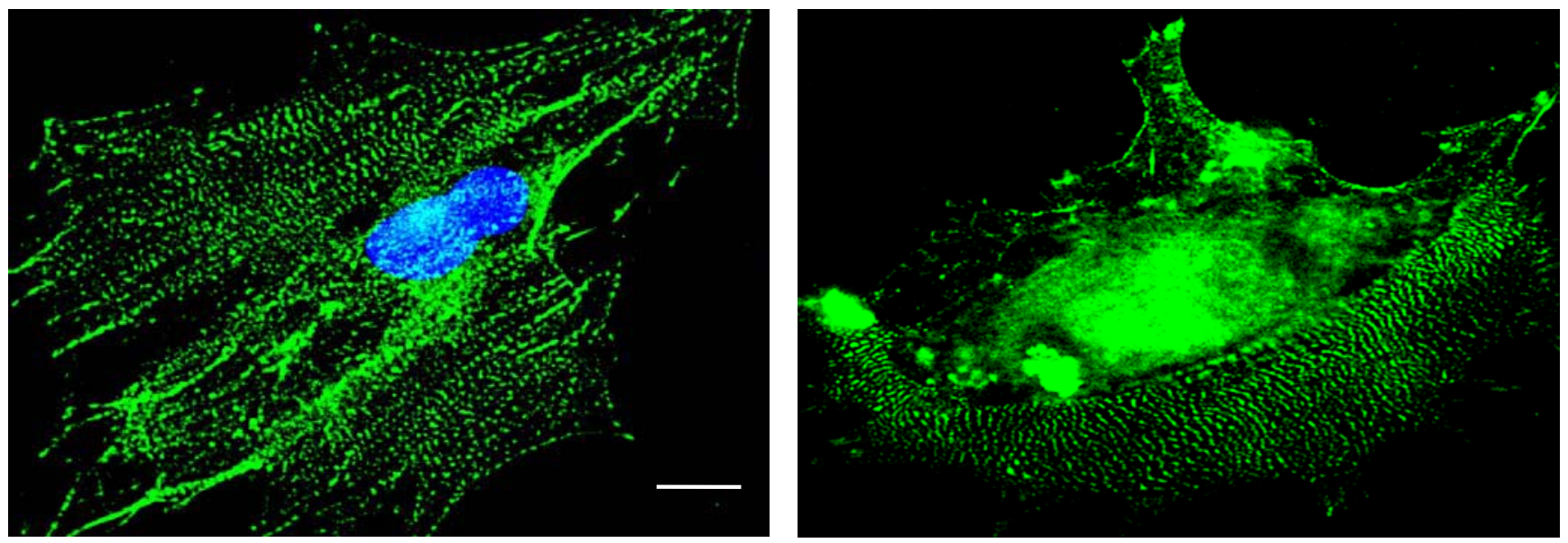

Fig. 1. Human cardiomyocyte-like cells show characteristic cardiomyocyte phenotype of sarcomeres with cross-striating Z-bands. Scale bar $=20 \mu \mathrm{m}$. 